the outset, and assuming-as is not impossible-that a free site can be obtained, it is reckoned that $\oint_{160,000}$ would be sufficient for the necessary buildings and equipment, and that the annual expenses on staff and service would not exceed $£ 20,000$, of which about two-thirds would be recouped by fees, leaving to be provided from endowment between $£ 6,000$ and $£ 7,000$ a year, which brings the total capital endowment estimated as required to $£ 375, \infty 00$

'I'o what quarter is the University to look for this necessary sum? On the Continent of Europe it would at once be recognized as a legitimate charge on the State. In our country that can hardly be. The tradition that professional education is no affair of the State is still deeply rooted in England. Even the modest subsidy annually granted by the Treasury to the English Colleges is given under proviso that no portion of it shall be used for the purposes of the medical school. On State aid we can count but little. In America, if we may judge from the accounts lately brought back by the Mosely Commissioners, the matter would also be speedily settled. Our Chancellor would need but to sally out, pay some half dozen judiciously planned morning calls, exercise the persuasiveness which he is universally allowed to possess, and the thing would be done. Have we no wealthy men in London capable of being fired by emulation of transatlantic gifts to education, who will make this modest benefaction their peculiar care? As we lately learned with so much gratification, a most auspicious beginning, at least, has been made. May we trust that it will be followed by speedy fruition, and that the list of subscribers already privately started will be covered without needless delay? Among them, one may safely predict, will be found not a few members of our own profession; but it must be clearly remembered and understood that it is no personal interest or advantage of the profession that is being sought. The object is in the fullest sense one of public concern, and it is to the public, not to the medical profession, that the appeal of the University is particularly addressed.

It would be a poor compliment to a University destined, as we hope, to a great academic position to let it be supposed that this introductory work is all that the Faculty of Medicine will eventually expect from it. At present it is our most urgent need, but there are more ambitious fields of work awaiting the University later. The idea that the principal duty of a university is the education of undergraduates, and that a bachelor's degree is the climax of a university career, is among the fading traditions that the nineteenth century bequeathed to us. In the United States the more advanced school of educationists already begin to regard the teaching of undergraduates as but a secondary function of a university, if indeed they would admit it to be a university function at all. The preparation of candidates for initial degrees they are disposed rather to relegate to a class of institutions of subordinate rank which in America are called "colleges." The real work of a university, it is argued by many, is that to which the attainment of an initial degree is only an introduction. "Graduate study," as Americans call it, is already with them a prominent feature of higher education, and even seven years ago, according to the reports I have already quoted, twenty-three American institutions were able to make up between them a total of 4,919 resident graduate students, an average of nearly 214 the importance, and indeed the necessity, of graduate study, and the number of members of our profession pursuing it in London in one shape or another would probably exceed anything that is to be found in America; but the provision which we have been able to make for it would, I fear, have to sustain a far less flattering comparison. It is certainly not yet so complete as to place any serious difficulty in the way of its absorption into the organization of the University, or to render the co-operation of a powerful university with it other than welcome. With the aid of the University we may perhaps one day see removed the weakness of the London system that has always been most apparent to foreigners; I mean the entire dependence of the academic position of a medical teacher upon the term of his hospital office, with the unavoidable result that some of our greatest clinicians have ceased to teach at the very time when their experience is ripest and their judgement at its greatest maturity.

May I venture, in conclusion, to deprecate a certain note of impatience that occasionally makes itself perceived in the medical world because the development of our University is not proceeding at as rapid a pace as we could wish? We must not expect impossibilities. To make up the arrears of two generations in a great capital was as huge a task as any university could have had committed to it, and some of the difficulties in the way have been very hard to surmount. That the constitution of our University is not an ideal one, that it may be open to the charge of cumbrousness, I, at least, am not concerned to deny; but machinery is of less importance than men ; and we need not complain overmuch of a constitution that has committed the interests of our science to such strong and able hands as those of the representatives it has upon the University Senate, and placed at the head of ourFaculty a man so singularly capable as its present Dean of grappling with the difficulties of the present situation. The: best compliment we can pay to the statesmanship and the self-sacrificing labours of Mr. Butlin and his fellow-workers in our behalf is, I submit, to give them a patient as well as am earnest support.

\section{HAEMATOMA AND HAEMATOCELE,}

A STUDY OF TWO CASES OF EARLY TUBAL PREgNANCY. BY ALBAN DORAN, F.R.C.S., Surgeon, Samaritan Free Hospital.

THE question of operative or expectant treatment in early extrauterine pregnancy is of high importance, but remains: unsettled, for authorities are not agreed as to what is the best course to pursue when haemorrhage sets in and stops. the early abnormal pregnancy. Haematocele, the result of intraperitoneal haemorrhage, may undoubtedly subside, as has been demonstrated by the experience of authorities to. whom further reference will be made, and by a case in my own practice presently to be related. A majority of gynaecologists, however, hold that haemorrhage into the peritoneal cavity, even when due to a bleeding mole and not to rupture of the tubal sac, demands operation. On the other hand, all authorities appear to admit that haematoma, the result of haemorrhage into the pelvic connective tissue outside the peritoneal cavity, is far more likely to be absorbed, and therefore does not as a rule render operative interference urgent. Even Taylor, who insists that cases of intraperitoneal haemorrhage from a ruptured tube or tubal mole rarely recover without operation, ${ }^{1}$ at the same time admits that when the tubal sac ruptures into the connective tissue space below the peritoneum a haematoma is the result, and in some instances the pressure and disturbance caused by this collection of blood is sufficient to stop the progress of the misplaced pregnancy. When this is the case the haemorrhage is slowly absorbed, and if the pregnancy be early and abortive, the products of conception undergo absorption also. $^{2}$

Roughly speaking, then, we are taught by certain living writers of repute that a haematocele implies great peril and demands operation, whilst it is generally admitted that a haematoma ${ }^{3}$ represents a far less dangerous ending to an interrupted tubal pregnancy and will subside if the patient be kept at rest.

The two following cases are of some interest because they do not support this teaching. For in the first. there were all the signs of tubal abortion with haemorrbagic mole and pelvic haematocele, yet the patient recovered and the haematocele underwent absorption. In the second a baematoma developed, but though the patient was kept at rest in hospital the effusion of blood did not subside. On the contrary, it ruptured its capsule, so that intraperitoneal haemorrhage occurred, rendering immediate operative interference needful.

CASE I. Bleeding tubal mole and pelvic haematocele. Clots passed over two months after last period, with pelvic pain and swelling in right forni: and iliac fossa, decidua passed a week later, $a$ mass with the characters of pelvic haematocele then developing, and gradually becoming harder and: smaller: No operation, prolonged rest: Period re-established within two nonths, becoming regular.

E. H., 24, was admitted into my wards in the Samaritan Free Hospital, on February Irth, 1903, for symptoms indicating ectopic gestation.

She had been married for over six years and had been twice pregnant. The first child was five years and nine months old, and was delivered at the seventh month by forceps, the second one was one year and eight months old and was delivered by forceps at term. Both children were reared, and the puerperium was uncomplicated after both labours. At the age of 13 this patient had been under treatment for anaemia, but she had never suffered from any serious illness.

The catamenia recommenced and continued regular during lactation 
after both labours, but the second child was only suckled for six weeks. There was scanty show every third week with much pain.

The last period occurred in the first week in December, rgo2. On February 7 th, r 903 , over two months later, some clots passed, and there was much pelvic pain. Haemorrhage continued, especlally at night. Dr. Williams of Connaught Street was called in on February 1 ith and found the patient in severe pain, with a temperature of ror $^{\circ}$ and a pulse of 120. She complained of much bearing-down pain at night, and was at once sent to the Samaritan Hospital.

The patient was very anaemic and thin, but quite free from cachexia or depression of spirits. I detected much distension in the right iliac region, with tenderness on palpation and resonance on percussion. No hard body could be defined. The uterus was almost fixed; the right fornix was occupied by a tender mass of about the size of a walnut hardly encroaching on Douglas's pouch, but connected with the swelling in the corresponding iliac fossa.

On February $x_{3}$ th the distension was more marked, very resonant and much less tender. The uterus was more fixed and displaced forwards, the mass in the right fornix larger. In the afternoon the decidua, which I now exhibit, was passed. The temperature was roo.2 ${ }^{\circ}$, the pulse 132 . There was absolutely no shock nor pain. The passage of the membrane afforded relief, and I decided to wait for a while before operating.

On the morning of February ${ }_{4}$ th I detected a firm mass in the right iliac fossa, cup-shaped, with the convexity upwards and extending across the middle line. The shrinking of the dimensions of this mass was very appreciable day by day. By the 20 th it was quite hard and round, the show, for the first time since admission, was absent. By March $2 n d$ the pelvic condition was more evident than before, for there was a firm, insensitive, convex body in the posterior fornix, continuous with the mass above the right groin. The uterus was drawn up in front of the mass, the cervix lying against the pubes.

The whole mass steadily contracted, and on March ${ }_{23} \mathrm{rd}$, when I discharged the patient, it projected 3 in. above the pubes, lying more in the middle line than before.

On April 6th I had an opportunity of examining her. The uterus now moved with a convex mass, which occupied the posterior and right fornices. The fundus could be clearly defined, and the upper part of the mass did not extend above the level of the fundus.

On April gth a true period with molimen occurred, lasting five days, and the show was rather free. A little powdery brownish blood was occasionally discharged until the end of April. Then the period became regular; by the end of June the mass behind the uterus had greatly diminished and the patient was in excellent health. I noted distinct pulsation at the base of the right broad ligament, as is observed in a tubal pregnancy still in progress. At the end of July the anaemia had almost disappeared and the pelvic pains had passed away. I afterwards heard that the patient was in very good health in October.

This case was to all appearances an instance of bleeding tubal mole ${ }^{*}$ in the right side and development, subsequent to the expulsion of the decidua, of a pelvic haematocele. That haematocele was cup-shaped above and formed inferiorly a convex mass projecting into the posterior vaginal fornix (Fig. 1).

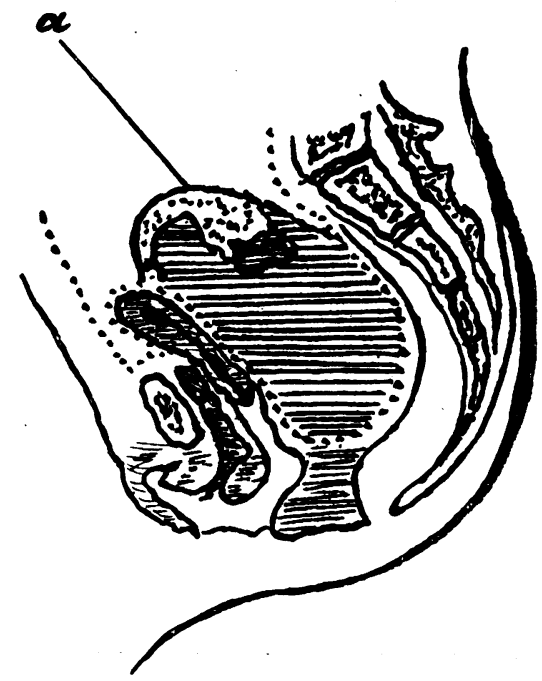

Fig. x. Case 1.-The dotted line' shows the peritoneum of Douglas's pouch in normal position. The fills the pouch (a) Fallopian pouch in normal position. The clot fils the pouch. (a) Fallopia

In other words, its lower part really occupied Douglas's pouch. This relation of the clot is of importance in association with

* I need not dwell on the pathology of this condition, on which so much light has been thrown by Cullingworth. Bland-Sutton, Lockyer, Handley, and others, as this commnnication deals with the question of intraperitoneal and extraperitoneal collections of blood rather than with tubal mole. the next case, where also a convex mass projected into the posterior fornix, but did not occupy Douglas's pouch, since that serous fold had been completely displaced by extraperitoneal haemorrhage.

I have repeatedly verified this combination of tubal mole and pelvic haematocele on the operating table; indeed, it must be familiar to all well versed in the surgery of the female pelvis. Masses of clot are discovered concealing the pelvic viscera. The uterus, the unaffected appendages, and the conspicuous tubal mole come into view when the clot is removed. Below and behind, Douglas's pouch is found full of blood, fluid or otherwise. Thus the effused blood, save that which is still inside the tubal mole, lies outside the uterus and appendages, which it covers up more or less completely. In the next case, on the contrary, the uterus, tubes, and broad ligaments completely covered the great collection of effused blood, only a small amount of which was beginning to escape inta the peritoneal cavity by leakage from the broad ligament.

Taylor, whose demonstration of intraperitoneal haematocele is well known for its clearness, teaches that "in women it is almost always caused by tubal pregnancy, sometimes by rupture of the tube, and sometimes by bleeding from the fimbriated end without rupture. The latter is the more common cause of intraperitoneal haematocele, and this bleeding from the unruptured tube is usually set up by the presence of a haemorrhagic mole within it." 4

Turning to treatment, the opinion of the same authority on that important matter is not so generally accepted as is his interpretation of the morbid anatomy of the condition in question. He maintains that an operation is always needed in cases of rupture of the tube and tubal mole ${ }^{5}$ where these haematoceles develop, the collection of blood being, in his opinion, "almost always" due to those complications. ${ }^{6} \mathrm{He}$ states that "occasionally, here and there," a patient recovers without operation, and admits that he has seen five or six such cases. ${ }^{7}$ He declares that " natural cure is rarely satisfactory, and that it contrasts somewhat unfavourably with operative methods." 8

Many gynaecologists follow Taylor's principles, but experience has shown that he has over-rated the perils implied by the development of a haematocele. I have had under my care a considerable number of cases during the last few years that have done very well without operation, though I, as well as certain more thorough advocates of expectant treatment. must make allowance for errors of diagnosis, the more so as I shall explain how another variety of haemorrhage in ectopic gestation, namely haematoma, may be mistaken for haematocele.

I admit that convalescence is without doubt more rapid after operation, but in my cases of spontaneous recovery the patients remain perfectly comfortable, with no abdominal cicatrix and with no ligatures on stumps-complications always to be dispensed with if possible. But several authorities are even more conservative than myself. My colleague, Dr. Lockyer, has published a valuable critical review on this question. ${ }^{9}$ Champneys's statistics are familiar to us all, ${ }^{10}$ but Lockyer also dwells upon the opinion of Veit. That gynaecologist lays down a principle in direct contradiction to Taylor's teaching. "We cannot assert," says he, "that when the ovum is dead dangers are absent. We can, however, state that subsequent to death of the ovum a favourable termination is much more probable. These cases will mostly recover without help." Loekyer himself concludes that the conservative treatment of ectopic pregnancy in the earlier months has established for itself a secure position in modern gynaecology. It is specially satisfactory in the treatment of tubal mole and diffuse haematoceles. Gossmann also believes in the frequency of spontaneous cure. ${ }^{11}$

When we turn to haematoma, sometimes called extraperitoneal haematocele, Taylor differs from many of us as to its relation to ectopic gestation. He demonstrates how a tubal sac may burst so as to discharge the ovum into a space which it makes for itself by forcing apart the layers of the broad ligament. In consequence an anterior or posterior tubo-ligamentary pregnancy develops. Taylor's theory is generally accepted, being based on sound anatomical and pathological evidence. In fact we all admit that the ovum may lie between the layers of the broad ligament. That being the case, we must further allow that blood from a ruptured tubal sac may also force itself into the broad ligament, in other words it will form a haematoma. Nevertheless, Taylor teaches that haematoma of the broad ligament is only in the minority of cases due to tubal pregnancy. ${ }^{12}$ 
I am of opinion that haematoma is more frequently the result of extrauterine pregnancy. In the case which I will now relate the extraperitoneal position of the clot and displacement of the pelvic peritoneum were made very manifest at the operation. There was a source of fallacy which led me to suspect before the operation that the clot lay in Douglas's pouch. I cannot heln thinking that many cases of haematoma have thus been diagnosed as haematocele.

CASE II. Haematoma following ruptuic of tubal sac: pain in right iliac fossa and vomting when period was due-four days later hacmorrhages and swelling above pubes steadily increasing and forming below a convex mass simulating a haematocele. Decidua passed over a month after beginning of

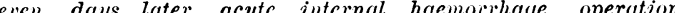
smploms electu ding pelvic peritoneum forming its capsule, right tube opening into hacmatoma
which leaked into peritoneal cavity. Removal of uterus, appendages and clot. Recovery.

A. B., 31, was admitted into my wards in the Samaritan Free Hospital on March ${ }_{4}$ th, r 903 , with symptoms indicating ectopic gestation. She had been married eleven years, and her first pregnancy ended normally two years after marriage. Two years later, when in the seventh week f her second pregnancy, she received a blow in the eye and aborted the curette was used in the Queen's Hospital, Birmingham, shortly afterwards. The third pregnancy ended one year and a-half later at term the fourth also terminated normally on March ${ }_{2} \mathrm{rd}$, 1902 but haemorrhages occurred during the puerperium and lasted for eleven weeks, when Dr. Davidson of Shepherd's Bush plugged the uterus and the bleeding ceased. The child had died in the fourth week. The catamenia returned, and were regular until January I 4th, rgo3, when free show appeared, lasting for four or five days. A fortnight later the patient suddenly "felt very languid." On February isth sharp pain was felt in the right iliac fossa, and she vomited twice. On the rgth haemorrhages set in ; they were slight, but the pains increased. Dr. Davidson kept her at rest and on March 8 th detected a lump above the pubes. She was seen a few days later by Dr. Lockyer, who sent her into my wards, having diagnosed ectopic gestation.

The patient on admission was highly anaemic: she had been slightly so for several months. The abdomen was distended with flatusi3 and very tender to touch. $\Lambda$ firm deposit could be felt in the hypogastrium; its upper limits lay within 3 in. of the umbilicus, and the blunt-edged fundus of the uterus could be defined high on its anterior surface.

On vaginal exannination I detected a big, firm mass, uniformly convex, in the posterior fornix, which made me suspect that it must be in Douglas's pouch-a haematocele, in fact: but it proved, as will be shown, to be extraperitoneal. The cervix was small and pushed upshown, to be extraperitoneal. The cervix was small and pushed upwards and forwar

The temperature on admission was ${ }_{102}{ }^{\circ}$ in the mouth, at the end of week it dropped to $99^{\circ}$, then it rose to $100^{\circ}$ at night and never fell to normal ; shortly before the operation it was r $00.2 \mathrm{O}$

Three days after admission, on March ${ }_{7} 7 \mathrm{th}$, I found that the decidua1 which I now exhibit, had been passed on the previous night. There was great trouble from constipation, and it was not easy to introduce an enema tube, as the mass pressed on the rectum. A long shreddy, shagg clot was passed on the r 8 th. The bowels were at length opened by aperients and the patient fared better for a few days.

On the evening of March 28 th a clot as big as a walnut was passed, and a few hours later violent pains, "like labour." as the patient described them, set in. At 6 a.m. on the 29 th, I was called up and found the patient in a state of collapse with a very rapirl feeble pulse. The swelling was distinctly larger and much more tense. There could be no doubt that internal haemorrhage was taking place.

From the first ectopic gestation seemed very probable, and the discharge of a decidua on the ${ }^{7}$ th made the patient's condition yet more clear. There was no evidence of fresh haemorrhage when the decidua membrane came away, so I thought that the haematocele, as it seemed to be, would gradually disappear. Several large haematoceles in my own practice have become absorbed. When the acute symptoms set in I concluded that there must be fresh intraperitoneal haemorrhage, and in order to arrest it I operated with the assistance of Dr. Lockyer, Dr. Belfrage administering gas and ether.

The pelvis was elevated throughout the operation. I made a free incision and found that the hard mass was the uterus drawn high up on the anterior aspect of a convex swelling, together with a greatly distended right Fallopian tube. The left tube, also much dilated, ran down the left border of the swelling. The great omentum adhered firmly to the fundus and to the right tubal sac. A small collection of recent clot las behind the omental adhesion in front of adherent small intestine and descending colon. These adhesions were detached.

I laid open the right tube. About $4 \mathrm{oz}$. of old, dry, brown clot were found in its canal, and then a big dark swelling came into view, forming as it were the floor of the dilated tubal cavity. I cut into the thin membranous tissue, consisting of organized clot, which formed the wall of the swelling, and then a great mass of coagula appeared, more recent than that which had filled the right tube. I removed no less than $4 \mathrm{lb}$. of this clot, which filled the whole pelvis.15

The patient's condition at this stage was very serious, and as the precise source of the haemorrhage could not be determined I tied both ovarian vessels, turned down an anterior flap of peritoneum from the lower part of the uterus, secured the uterine vessels, and amputated the uterus through the upper part of the cervix. That organ then came avay with both tuhes and ovaries and with the great dome of membrane which had capped the mass of elot. That displaced memhrane consisted of the opened up l,road ligament and peritoneum, which had unce formed Douglas's pouch.

The pelvis was drained with iodoform gauze and the abdominal wound closed, except at its lower angle.

Over one pint of saline fluid was in jected under the breast during the operation, and a saline enema was administered. After the abrlominal wound had been closed $1 \frac{1}{2}$ pint of saline fluid was injected into the leit median basilic vein.

When the patient was put back to bed her condition was very unfavourable. At the end of three-quarters of an hour she seemed a little stronger, though there was no pulse at the wrist. Brandy and digitalis were given-enemata of lot water could not be retained. At noon the temperature had risen to $105.2^{\circ}$, and there was a rigor. I observed marked facial spasms which lasted for several minutes. Half an hour later the pulse could be felt. By 6 p.m., after free administration of digitalis and brandy, the temperature had fallen to $103^{\circ} \mathrm{F}$., the pulse was 150 , but distinct and regular. At io p.m. temperature $101.6^{\circ} \mathrm{F}$, pulse 138 , and the patient took barley-water. The absence of vomiting was remarkable.

Twenty-four hours after the operation the patient seemed much stronger and flatus passed naturally. I removed the gauze, and little or no oozing followed. A rubber tube was left in the lower angle of the wound for a few days. The cavity was washed out with antiseptic solutions for about four weeks, some sloughy tissue coming away. The anaemia was relieved by suitable treatment, and the patient left hospital with a sinus in the lower angle of the wound four inches deep. The general health was good.

I last saw the patient on March 8th, 1904; she had gaineit flesh and was much less anaemic. On August 9 th she noticed a show of blood which lasted for two days, on October I th a much more copious discharge set in and continued for four days. ${ }^{16}$ The show recurred with regularity every four weeks until February, when it appeared twice, and the patient suffered from flushings as though a premature menopause was impending. The sinus was 2 in. deep. The long cicatrix of the abdominal wound was firm. On vaginal examination the cervix was found to be quite movable. The fornices were free.

This case was clearly an example of haematoma caused by rupture of a tubal sac between the layers of the corresponding broad ligament (Fig 2 ). The accident must have occurred

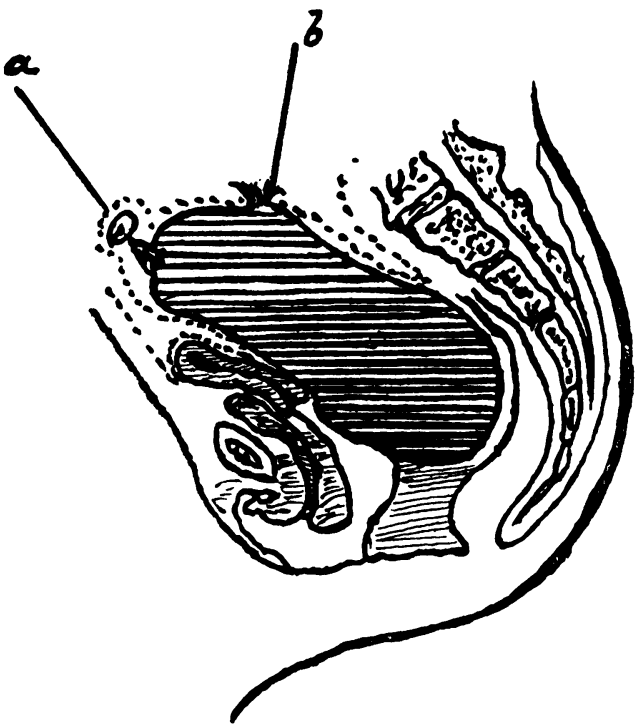

Fig. 2. Case II.-The dotted line shows the pelvic peritoneum completely displaced upwards by the clot. (a) Dilated right Fallopian tube, which liad ruptured into the parar

about February 15 th, and the ovum was destroyed, else a posterior tubo-ligamentary pregnancy would have developed. The haemorrhage continued, until at length the whole pelvic peritoneum was heaved up. That part which had formed Douglas's pouch became the superior and posterior part of the capsule which covered the great mass of clot. The uterus and appendages were raised up with the anterior layer of the broad ligament so as to constitute the anterior part of the 
capsule. The lower part of the clot free in the pelvic connective tissue lay, not in Douglas's pouch, but jn its site and could be detected by touch as a convex mass behind the cervix.

On the night of March 28th, nearly six wepks after the rupture of the tube, the capsule leaked a little posteriorly to its superior limits at the point of adhesion to the omentum.

On this occasion there was sharp pain, such as has been noted in intraperitoneal haemorrhage, but the patient's sufferings must have been largely due to the tension of the capsule of peritoneum, a necessary result of the renewed haemorrhage.

Had a fetus escaped through a rent in the capsule instead of a clot, then, granting that the patient and fetus had survived, a tubo-abdominal pregnancy of the fourth class, according to Taylor, ${ }^{17}$ would have developed. Earlier writers believed that most abdominal pregnancies were established in that manner, which implied that abdominal was secondary to tubo-ligamentary pregnancy. ${ }^{1 s}$

The cause of the renewed haemorrhage in Case II was not clear. Most probubly it was due to straining at stool. There were no solid motions in the intestinal canal at the time, but, on the contrary, looseness of the bowels following free purgation by magnesium sulphate which had greatly relieved the flatulence. In order to hasten the escape of flatus and liquid motion patients often strain at stool.

The most prominent physical sign, after the presence of a tumour in the hypogastrium, was the convex mass behind the cervix. A similar kind of swelling is to be detected when there is a pelvic haematocele and the blood in Douglas's pouch has coagulated; a tubal sac in the same position also forms a convex mass behind the cervix. ${ }^{19}$ But there is no Douglas's pouch in this case-a fact which was made clear at the operation. All collections of clot, as well as all cysts and fibroids which burrow thoroughly into the posterior fold of the mesometrium, must, if they continue to grow, displace that portion of the peritoneum which constitutes Douglas's pouch, so that it will lie on the top and back of the clot or tumour. This displacement of the peritoneum is very plainly seen when a large fibroid of the broad ligament is exposed and enucleated from its serous investment. I have demonstrated at full length this displacement in the Harveian Lectures for $1902 .^{20}$

Taylor, ${ }^{21}$ in treating of broad ligament haematoma, observes that in some cases " by burrowing' in front of the rectum low down in (sic) the pouch of Douglas it may produce a welldefined tumour behind the uterus that closely simulates inter-peritoneal swelling of a distended and adherent tube." But a broad ligament haematoma cannot be in Douglas's pouch, as it is essentially an extraperitoneal condition. Taylor illustrates the above remarks by a drawing from Hart and Carter's work, ${ }^{22}$ on inspecting: it that author's meaning at once becomes clear. The clot is represented behind the posterior layer of Douglas's pouch, being, in the case illustrated, insufficient in bulk to heave up the whole pouch in the manner which I have already endeavoured to explain. Thus the relations of one form of small haematoma are proved by Hart and Carter's section, whilst the relations of an unusually large haematoma were made evident by the condition of the affected parts which I detected when operating on Case II. ${ }^{23}$

Thus these two cases indicate, in the first place, that haematoma is not so rare a result of interrupted extrauterine pregnancy as is generally taught, and that it may be mistaken for haematocele. Haematoma is, however, decidedly less frequent than haematocele in relation to ectopic gestation. For the tubal sac is more likely to discharge its contents through the ostium into the peritoneal cavity, or to burst into that cavity, than to rupture between the folds of the broad ligament. When the broad ligament is opened $n p$ in this manner experience has proved that, instead of a haematoma forming, the ovum not rarely continues to develop, constituting the tubo-ligamentary pregnancy, anterior or posterior, of Taylor. There remains a considerable minority of cases where the ovum is destroyed and a true haematoma develops and displaces the pelvic peritoneum upwards after the manner of a tubo-ligamentary sac. In such a case the lower part of the haematoma, bulging behind the cervix, may be mistaken for a haematocele occupying Douglas's pouch, though in reality that pouch no longer exists, its peritoneum lying above the haematoma.

Secondly, the haematoma of extrauterine gestation, even when developed early, is not so innocuous, as compared with haematocele, as certain authorities are inclined to believe.
The peritoneal capsule may yield, so that dangerous intraperitoneal haemorrhage ensues.

Thirdly, there can be no' doubt of the truth of the prevalent theory that haematocele is a very frequent result of interrupted tubal gestation. At the same time, whilst the dangers of haematoma have been underrated, the perils of haematocele have been exaggerated, at least as regards the earlier stages of ectopic gestation. The haematocele often signifies that the issue of blood from a tubal mole has permanently ceased, nor is it certain that the same may not be said of many cases of early rupture of the tube.

In conclusion, we must admit that the importance of faithful clinical study of extrauterine pregnancy from its early recognizable stages cannot be over-estimated. There is much that we can safely teach, yet there remains more that we must learn about ectopic gestation; above all, as to the relation of prognosis to treatment.

\section{Notrauterine Pregnancy REFBRENCES.}

1 Extrauterine Pregnancy, $p 148.2$ Ibid., p. 64. 3 That is to say subperitoneal haemorrhage, as defined abore. "The term "tubal haematoma" applied to haemorrhagic mole is confusing, and is therefore not employed in this communication. 4 Ibid.; p. 33. 3 Ibid., p. 148. ${ }^{6}$ Ibld. P. 65. ment of Extrauterine Pregnancy." Journ. of Obstel. and Gynaec. of the Brit. Empire, vol. ii. p. 173. See also, for a recent instructive discussion on the same theme, Gustav Klein's "Operiren oder nicht Operiren bei Eileiter Gehwangerschaft und Haematocele?" Monats. f. Geb. u. Gyn., December, 1903, p. 897. The conflicting evidence of Klein and Gossmann deserves pady of the Natural History of Tubal Gestation," illustrated by a series of 75 original cases. Journ. of Obstet. and Gyn. of Brit. Empire, vol. 1 p. 585 . 11 Gustav Klein, loc. cit. 12 Ibid., p. 65. 13 This symptom would favour the diagnosis for examining and mounting the deciduae from these two cases. 15 No trace of a fetus could be detected. The pregnancy had been interrupted at a very early stage $16 \mathrm{It}$ is very doubtful if any ovarian tissue could have been left. as both ovaries were easily removed with the body of the uterus. In oöphorectomy for the cure of uterine fibroids it was quite otherwise. I have discussed this question in the Harveian Leotures (Lecture II, Lancet, ol. i, 1903, p. 415. 17 Ibid., p. 58 . 18 Ibid., pp. 47, 48 . 19 Taylor rightly lays stress on the fact that a swelling behind the cervix in these cases may be the gravid tube and not a haematocele or haematoma. For his view of the relations of the gravid tube to the haematocele, see ibid., p. 113, par. 10, 20 Lecture I, Lancet, vol. i, 1900, p. 350; Section, "The Surgical Anatomy of the Broad and Ovarian Ligamentts.; when operating upon a case of hydatid cyst burrowing in and beyond the broad ligament. "J'essaie en vain de luxer la tumeur hors du Douglas; elle souleve le peritoine pelvien en s'en coiffant." (The term is most expressive; the clot in my case was coiffe, by the pelvic peritoneum). See Savariaud, "Kystes Hydatiques du Ligament Large et du Grand Epiploon,"

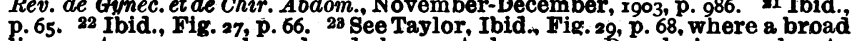
p.65. 22 Ibid., Fig. 27, p. 66. 23 See Taylor, Ibid.. Fig. 29, p.68, where a broad ligament pregnancy has already begun to heare up Douglas's pouch. As and intelligible." Lawson Tait's well-known "jelly-fish," convex above matoma.

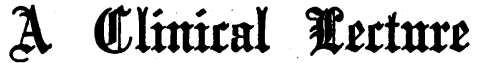

\section{TOTAL EXTIRPATION OF THE PROSTATE FOR RADICAL CURE OF ENLARGEMENT OF \\ THAT ORGAN.}

Delivered at the Medical Graduates' College and Polyclinic.

By P. J. FREYER, M.A., M.D., M.CH., Surgeon, St Peter's Hospital, London.

Gentlemen,-In a lecture delivered by me in this College about two and a-half years ago, and subsequently published in the British Mredical Journal, ${ }^{1}$ I had the honour of placing before you full details of my operation of total extirpation of the prostate for radical cure of enlargement of that organ. I have since then from time to time, here and elsewhere, lectured on several further series of cases of this operation, and published the lectures in the same Journal. ${ }^{2}$ In this manner complete details of my first 53 cases of this operation have been submitted for the consideration of the profession at large. I have now to bring to your notice a further series of 20 cases of the operation, carrying my work in this direction down to the end of 1903. I cannot inflict on you full details of these operations, even were it possible to do so in the limited time at our disposal. I shall therefore content myself with giving brief notes of the majority of the cases, dwelling more at length on those that illustrate some interesting or novel feature in connexion with the operation. 